\title{
Rigid Connection with Granite Chips in the Timber-Concrete Composite
}

\author{
Karina Buka-Vaivade \\ department of Structural Engineering \\ Riga Technical University \\ Riga, Latvia \\ Karina.Buka.Vaivade@gmail.com \\ Leonids Pakrastins \\ department of Structural Engineering \\ Riga Technical University \\ Riga, Latvia \\ Leonids.Pakrastins@rtu.lv
}

\author{
Dmitrijs Serdjuks \\ department of Structural Engineering \\ Riga Technical University \\ Riga, Latvia \\ Dmitrijs.Serdjuks@rtu.lv \\ Viktors Mironovs \\ department of Structural Engineering \\ Riga Technical University \\ Riga, Latvia \\ Viktors.Mironovs@rtu.lv
}

\author{
Andrejs Podkoritovs \\ department of Structural Engineering \\ Riga Technical University \\ Riga, Latvia \\ Andrejs.Podkoritovs@gmail.com
}

Abstract - Timber-concrete composite panels enables to combine advantages of pure timber and pure concrete panels in one structural member especially in the case, when the rigid timber-concrete connection is provided. The effectiveness of timber and concrete use and load-carrying capacity of the timber-concrete composite panels will grow in the case. The new concept of rigid timber to concrete connection was developed by the using of the granite chips as the keys to provide high quality of the glued connection. Behaviour of the timber-concrete composite panels were investigated by finite element method and laboratorian experiment. Three timber-concrete composite panels in combination with carbon fibre reinforced plastic composite tapes in the tension zone with the span $1.8 \mathrm{~m}$ were statically loaded till the failure by the scheme of three-point bending. One specimen was produced by dry method, by gluing together cross-laminated timber panel and prefabricated concrete panel. Timber-concrete connection of the other two specimens was provided by the granite chips, which were glued on the surface of the cross-laminated timber by epoxy, and then wet concrete was placed. Dimensions of the crushed granite pieces changes within the limits from 16 to $25 \mathrm{~mm}$. The current study focuses on determining the effect of the use of granite chips for timber-concrete composite panels with adhesive connection between layers. The effect of the use of granite chips in rigid connection is determined by comparison of mid-span displacements and level of failure load of the two variants of the timber-concrete composite panels. Three-dimensional finite element models of timberconcrete composite with rigid connection was developed and validated by experiment data. Obtained results shown, that the use of the granite chips in rigid timber to concrete connection allow to make a quality rigid connection.
Possibility to increase by $28 \%$ level of failure load of the timber-concrete composite panels by the adding of granite chips was stated. Maximal vertical mid-span displacements of the panels decrease about 3.8 times at the same time.

Keywords - adhesive connection, bending test, carbon fibre reinforced plastic, finite element method, glued connection, rigid connection, timber-concrete composite, wood-concrete composite.

\section{INTRODUCTION}

Effectiveness of timber-concrete composite (TCC) structural members strongly dependent from the type of timber to concrete connection. Semi-rigid and rigid once are two types of timber to concrete connections in hybrid timber-concrete composite structural members, which are used now in the practice [1], [2]. Studies shows that the adhesive composite connection of the timber-concrete structural members is more effective in comparison with the semi-rigid one so as provides higher bending stiffness and leads to smaller deflections and a better structural members behaviour, including higher natural frequency, which is a very important characteristic of the floor structures [3] - [10].

Timber component in timber-concrete panels very often is presented by the cross-laminated timber (CLT). Crosslaminated timber is a renewable structural material, which possesses a decreased level of anisotropy in comparison with the solid and glued timber. CLT could be used for load-bearing walls and panels of multi-storey timber

\section{Online ISSN 2256-070X


buildings as well as the decking structures of pedestrian and road bridges [11].

Nowadays, two technologies to produce glued connection of the TCC are known [12]. "Dry" is the gluing of timber with a precast concrete slab; "wet" - is a technology when a fresh concrete is placed on a freshly applied layer of glue. Both techniques have high risk of forming a poor-quality rigid connection in TCC, and there are difficulties in controlling the quality of the glued connection. So, for popularization of the rigid connection in TCC it is necessary to offer more optimal connection production technology.

Providing of the rigid connection between CLT and concrete layers by gluing granite chips on the surface of the CLT panel probably enables to obtain timber-concrete composite structural member with increased stiffness [13] - [15]. So, the objective of current study is investigation of influence of the granite chips in the rigid timber to concrete connection on the behaviour of timber-concrete composite structural members subjected to flexure.

\section{MATERIALS AND METHODS}

A timber-concrete composite panel with CLT as timber component and additional strengthening by the carbon fibre reinforced plastic tape in the tension zone subjected to the three-point bending was considered as an object of this investigation. Influence of the granite chips in the rigid timber to concrete connection on the behaviour of hybrid timber-concrete composite structural members subjected to flexure was evaluated based on the laboratorian experiments and finite element method (FEM) analyses. Numerical model of TCC specimen (Fig.1.) was developed with structural analysis program RFEM. The solid finite elements were used for FEM model development. 3D orthotropic elastic material model was used for CLT elements, for carbon fibre reinforced plastic was used isotropic non-linear material model and 3D isotropic Mazars' damage material model was used with non-linear stress-strain diagram for concrete layer. For 3D numerical model of the TCC specimens contact solid between concrete and CLT layers is defined with full force transmission. Target length of FE equal to $0.02 \mathrm{~m}$ and 100 load increments was used for TCC model. The model of TCC was divided into the finite elements by the rectangular mesh.

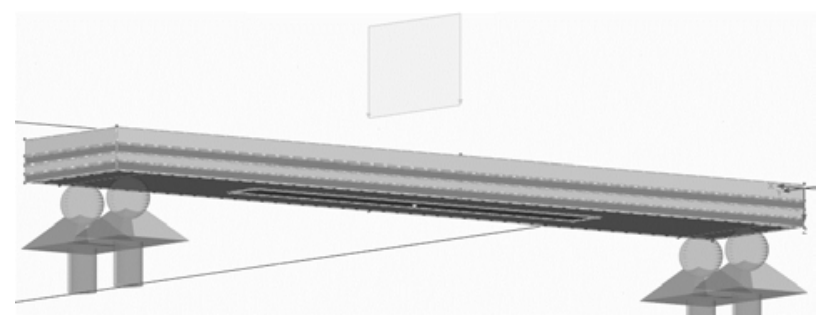

Fig. 1. FEM model of timber-concrete composite with carbon fibre reinforced plastic tape developed by the software RFEM.
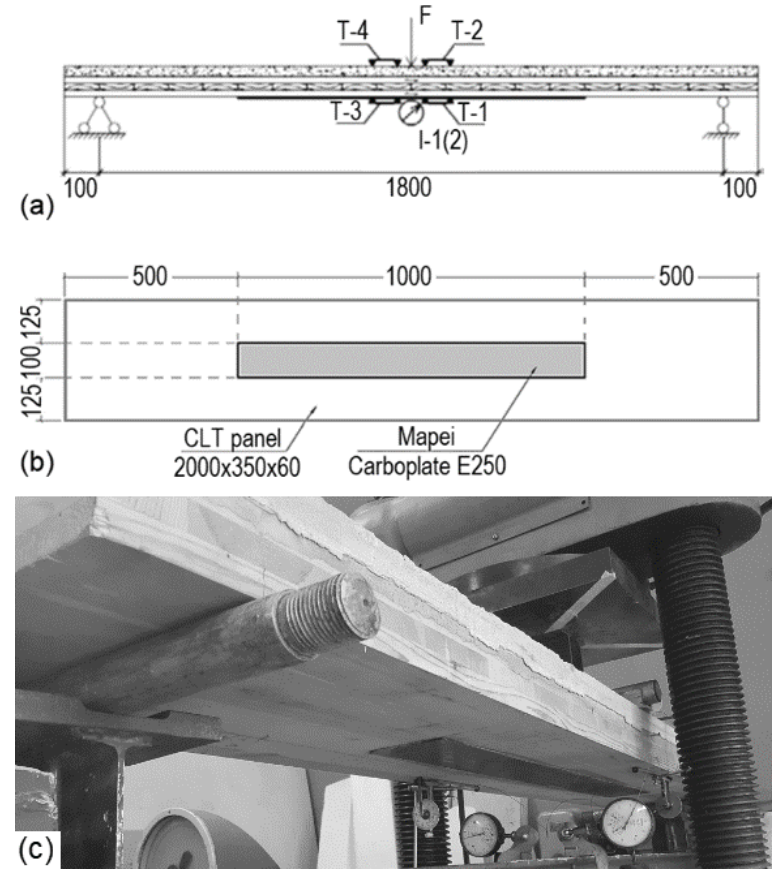

Fig. 2. TCC panel (a) design scheme; (b) placement of carbon fiber reinforced tape on its surface in the tensioned zone, (c) placement in testing machine.

The first laboratorian experiment was carried to investigate the behaviour of the timber-concrete composite produced by dry method [16]. Timber to concrete connection in TCC panels was provided by gluing CLT panel with prefabricated concrete panel by the epoxy Sicadur 330. Timber-concrete composite panels consist of the CLT components, which are strengthened by the carbon fibre reinforced plastic tape Mapei Carboplate E250 in the tensioned zone and with the layer of finishing mass Sacret BAM with thickness of $30 \mathrm{~mm}$ in compressed zone.

The cross-laminated timber base was formed by the three layers of strength class C24 timber boards. Thickness of each board layer is equal to $20 \mathrm{~mm}$. Fibres of outer layers are oriented parallel to the longitudinal axis of the panels. The panels have length, width and thickness equal to 2000, 350 and $60 \mathrm{~mm}$, correspondingly. The panels were produced by the Sconto enterprise, Ltd, Jelgava, Latvia.

The second laboratorian experiment was carried out to check influence of the granite chips in the rigid timber to concrete connection on the behaviour of timber-concrete composite panel. Two specimens with the same dimensions as the specimen from the first laboratorian experiment were prepared. Timber to concrete connection was provided by the granite chips with dimensions changing within the limits from 16 to $25 \mathrm{~mm}$ glued to the surface of CLT by the epoxy Sikadur 330 [17].

Design scheme of the laboratorian experiments and specimen placement in testing machine are shown on the Fig.2. Two groups of strain measuring devices and one group of deflectometers were used during the static loading of the timber-concrete composite. Strain measuring devices T-2 and T-4 were placed in compressed zone. Strain measuring devices T-1 and T-3 were placed in tensioned 
zone on the surface of the cross-laminated timber. A group of the deflectometers I- 1 and I-2 was placed in the middle of the span. Precision of the maximum vertical displacements and absolute deformations measurements was equal to $0.01 . \mathrm{mm}$ and $0.001 \mathrm{~mm}$, correspondingly. All specimens were loaded until the failure to determine their level of failure load.

\section{RESUlTS AND DiSCUSSION}

The load-displacement curves of the specimens of TCC subjected to the three-point bending are shown on the Fig.3. The dependences of TCC specimens were obtained by the experiment and developed 3D numerical model, for the TCC with granite chips there are shown curve with average values of two specimens.

As it can be seen from load-displacement curve of TCC specimen with glued connection with granite chips, the behaviour of the specimens is linear up to about $15 \mathrm{kN}$, then increasing of specimen's stiffness is observed. According to the laboratory test, mid-span displacement of the TCC specimen with granite chips at the load level equal to $15 \mathrm{kN}$ is $3.18 \mathrm{~mm}$, while the calculated by 3D non-linear numerical model corresponding displacement is $3.50 \mathrm{~mm}$. $3 \mathrm{D}$ model produces little more conservative results of the behaviour of the TCC specimens with granite chips subjected to the three-point bending than data obtained by the experiment. The curve obtained with the $3 \mathrm{D}$ model very accurately describes the behaviour of the specimen with granite chips in the initial linear stage. It can be concluded, that developed model is safe for prediction of the behaviour of TCC with rigid connection provided by use of granite chips.

The behaviour of the TCC specimen produced by dry technic without gluing of granite chips on the surface of the CLT is completely different in comparison with TCC specimen where new concept of rigid connection with granite chips is used. According to the laboratory test, midspan displacement of the TCC specimen without granite chips at the load level equal to $30 \mathrm{kN}$ is $22.90 \mathrm{~mm}$, for TCC specimen with granite chips value of mid-span displacements at the same load level was only $5.77 \mathrm{~mm}$.

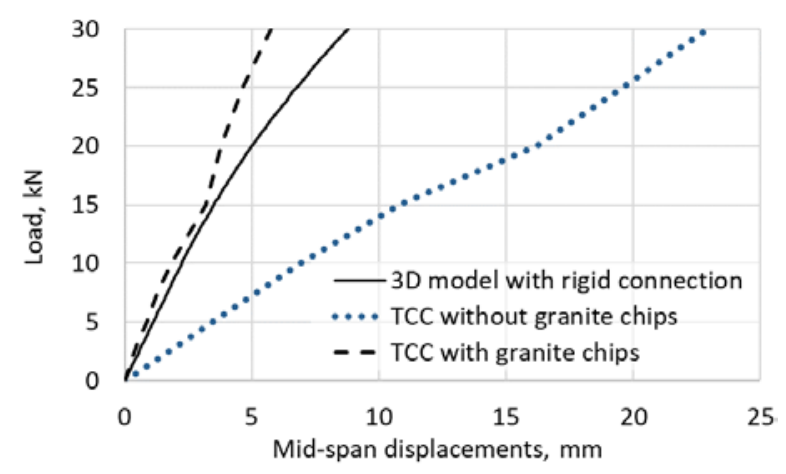

Fig. 3. Load-displacement curves for TCC specimens.

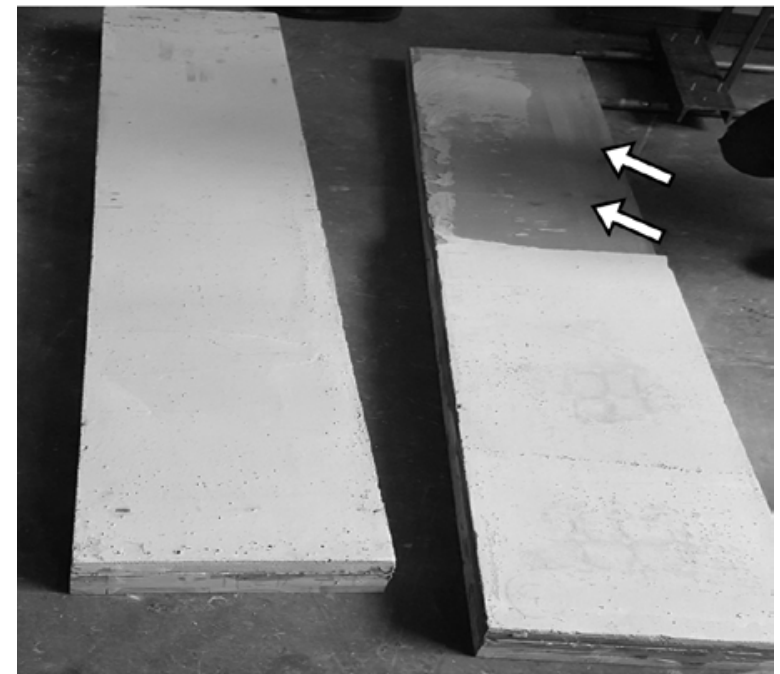

Fig. 4. Failure of the TCC specimen produced by dry technic without gluing of granite chips.

Results obtained by bending tests and FEM analyses show, that connection of the TCC specimen without granite chips is not rigid. The reason for this is the main problem of this type of connection, it is the difficulty to ensure complete and high-quality gluing of the layers. Splitting of the concrete layer from the CLT panel after collapse can be seen in Fig.4. It can be seen that a quality connection was formed only on about $40 \%$ of all connection surface. A similar result was obtained in testing of small-scale specimens. Fig. 5 shows the collapse scenes for small-scale TCC specimens with and without granite chips in the glued connection. In the TCC specimen without granite chips (Fig.5. (a)) splitting of the concrete layer takes place at the glued connection. In the case of the TCC specimen with the proposed connection concept with granite chips (Fig.5. (b)) it can be seen composite action of specimen and collapse on concrete layer.

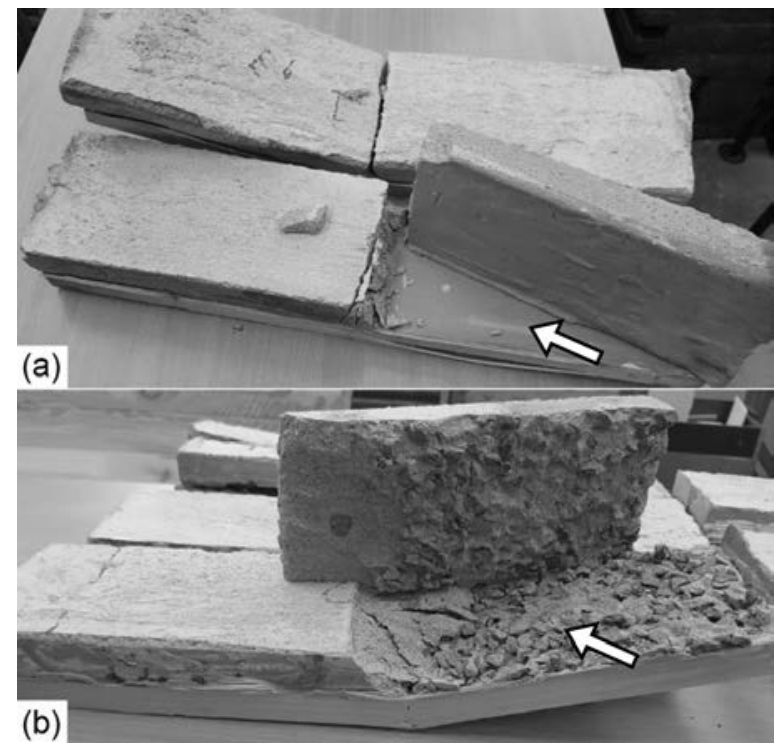

Fig. 5. Failure mode of the TCC small-scale specimens (a) without granite chips in glued connection, (b) with granite chips. 
According to the laboratory tests, level of failure load for TCC specimen without use of granite chips with span $1.8 \mathrm{~m}$ in tree-point bending is equal to $32 \mathrm{kN}$. For TCC specimen with rigid connection provided by granite chips use the failure load equal to $41 \mathrm{kN}$ was obtained.

\section{CONCLUSIONS}

Results of the laboratory experiments shows that proposed concept of rigid adhesive connection with gluing of granite chips on the surface of timber layer in timberconcrete composite provides good connection quality and full composite action.

Developed 3D numerical model of timber-concrete composite member subjected to the flexure with rigid connection and full composite action with sufficient precision describes the behaviour of the TCC specimen where connection between layers was provided by gluing of granite chips on timber component surface and after that placing wet concrete layer. In this case, quality of the glued granite chips can be assessed visually but bonding between concrete matrix and granite chips as aggregates of concrete is developed naturally.

Based on the obtained data, an increase in stiffness of the TCC specimens with granite chips has been observed. On the load level of $30 \mathrm{kN} 1.52$ times less mid-span displacements of the TCC specimen with granite chips was obtained in comparison with displacement calculated by developed numerical model of timber-concrete composite with full composite action.

The difference in the failure load level between timberconcrete composite specimen with and without use of granite chips in connection between material layers obtained by experimental bending tests is about $28 \%$. Timber-concrete composite with proposed connection technology picks up greater load level than TCC without granite chips in connection.

Possibility to increase by $28 \%$ level of failure load of the timber-concrete composite panels by the adding of granite chips was stated. Maximal vertical mid-span displacements of the panels decrease about 3.8 times at the same time.

At the load level equal to $30 \mathrm{kN}$ by timber-concrete composite specimen with granite chips in timber to concrete connection it is possible to obtain at least 3.8 times less vertical mid-span displacements than by timberconcrete composite specimen without granite chips.

\section{ACKNOWLEDGMENTS}

This research was supported by Riga Technical University's Doctoral Grant programme and Latvian Council of Science funded project "Method of correlation of coaxial accelerations in 6-D space for quality assessment of structural joints (COACCEL)” (Nr. lzp-2020/1-0240).

\section{REFERENCES}

[1] T. Tannert, A. Gerber and T. Vallee, "Hybrid adhesively bonded timber-concrete-composite floors," International Journal of Adhesion and Adhesives, vol. 97, Nr. 102490, 2020. DOI: 10.1016/j.ijadhadh.2019.102490

[2] M. Fragiacomo, A. Gregori, J. Xue, C. Demartino and M. Toso, "Timber-concrete composite bridges: Three case studies," Journal of Traffic and Transportation Engineering (English Edition), vol. 5, pp. 429-438, 2018. DOI: 10.1016/j.jtte.2018.09.001

[3] J. Kanocz, V Bajzecerova and S. Steller, "Timber - concrete composite elements with various composite connections. Part 1: screwed connection," Wood Research, vol. 58, pp. 555-570, 2013.

[4] J. Kanocz and V Bajzecerova, "Timber - concrete composite elements with various composite connections. Part 3: adhesive connection," Wood Research, vol. 60, pp. 939-952, 2015.

[5] M. Brunner, M. Romer and M. Schnüriger, "Timber-concretecomposite with an adhesive connector (wet on wet process)," Materials and Structures/Materiaux et Constructions, vol. 40, pp. 119-126, 2007. DOI: 10.1617/s11527-006-9154-4

[6] J.H. Negrao, F.M. Oliveira and C.L. Oliveira, "Investigation on timber-concrete glued composites," In: 9th World Conference on Timber Engineering (WCTE 2006). Portland, Oregon, USA, 2006.

[7] M. Al Ali, V. Bajzecerova and V. Kvocak, "Design methods of timber-concrete composite ceiling structure," Magazine of Civil Engineering, vol. 73(5), pp. 88-95, 2017. DOI: 10.18720/MCE.73.8

[8] V. Mironovs, A. Tatarinov, and S. Gorbacova, "Expanding Application of Perforated Metal Materials," In: Construction and Architecture IOP Conference Series: Materials Science and Engineering, vol. 251(1), Nr. 012027, 2017. DOI: 10.1088/1757899X/251/1/012027

[9] M. V. Gravit, D. Serdjuks, A. V. Bardin, V. Prusakov and K. BukaVaivade, "Fire design methods for structures with timber framework," Magazine of Civil Engineering, vol. 85, pp. 92-106, 2019. DOI: 10.18720/MCE.85.8

[10] M. N. Kirsanov, "Lower estimate of the fundamental frequency of natural oscillations of a truss with an arbitrary number of panels," Vestnik MGSU, vol. 14(7), pp. 844-851, 2019. DOI: 10.22227/1997-0935.2019.7.844-851

[11] K. Buka-Vaivade, D. Serdjuks, V. Goremikins, A. Vilguts and L Pakrastins, "Experimental verification of design procedure for elements from cross-laminated timber," Procedia Engineering, vol. 172, pp. 1212-1219, 2017. DOI: 10.1016/j.proeng.2017.02.142

[12] A. Dias, J. Schänzlin and P. Dietsch, "Design of timber-concrete composite structures", Aachen: Shaker Verlag GmbH, 2018.

[13] R. Vasiljevs, D. Serdjuks, K. Buka-Vaivade, A. Podkoritovs and N. Vatin, "Load-carrying capacity of timber-concrete composite panels," Magazine of Civil Engineering, vol. 93, pp. 60-70, 2020. DOI: 10.18720/MCE.93.6

[14] R. Vasiljevs, D. Serdjuks, J. Gerasimova, K. Buka-Vaivade and A. Orhun Erüz, "Behaviour of Timber-Concrete Joints in Hybrid Members Subjected to Flexure," IOP Conference Series: Materials Science and Engineering, vol. 660, Nr. 012050, 2019. DOI: 10.1088/1757-899X/660/1/012050

[15] A. Skincs, D. Serdjuks, K. Buka-Vaivade, V. Goremikins and A.Y. Mohamed, "Steel and composite tapes in timber to concrete joint," Lecture Notes in Civil Engineering, vol. 141, pp. 68-79, 2021.

[16] J. Gerasimova, "Testing of design method for hybrid elements subjected to flexure," M.S. thesis, Riga Technical university, Riga, Latvia, 2017.

[17] R. Vasiljevs, "Load-carrying Capacity Analyse for Hybrid Composite Member," M.S. thesis, Riga Technical university, Riga, Latvia, 2018 